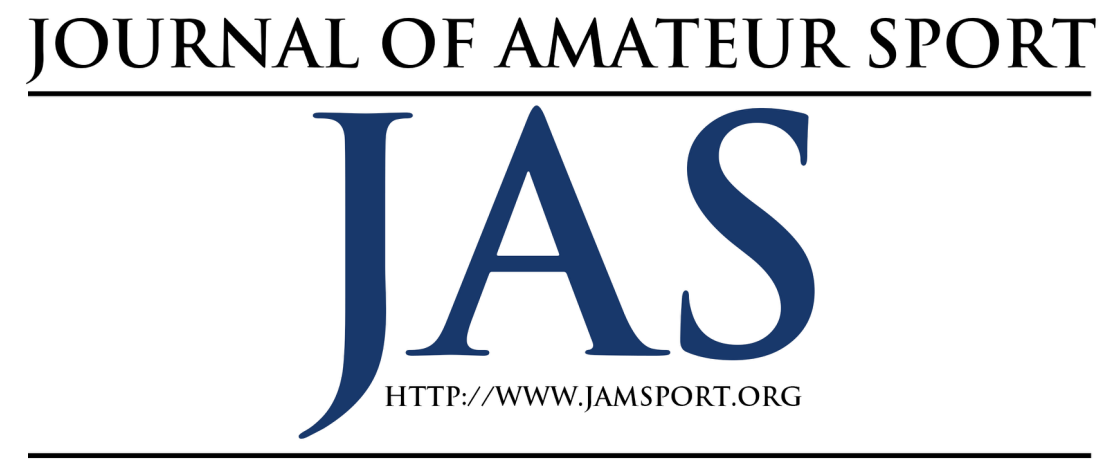

\title{
Formation and Function of a Collegiate Athletics Sustainability Committee
}

\author{
Brian P. McCullough ${ }^{1}$ \\ Elodie Wendling ${ }^{3}$ \\ ${ }^{1}$ Seattle University \\ ${ }^{2}$ Georgia State University \\ ${ }^{3}$ University of Florida
}

Timothy Kellison ${ }^{2}$

\begin{abstract}
Institutions of higher learning may be considered dual-identity organizations because of the perceived distinctiveness between universities' academic and athletic missions. One way in which these barriers can be weakened is through cross-sector social partnerships (CSSPs), a form of collaborative engagement aimed at achieving a common societal goal. In this study, we examine the formation of a universitydirected CSSP focused on enhancing environmentally sustainable initiatives within the Athletic Department. Interviews with 11 members of a so-called Green Team illustrate the processes of boundary spanning and boundary blurring. As demonstrated in the article, boundary spanning occurred under the leadership of a "champion" that assembled a team of stakeholders to assist with the major renovation of a pro-environmental football stadium. Though the sustainability committee has a common goal, not all experiences of Green Team members have been the same. In light of these differences, we identify key barriers and prescribe solutions that can lead to the realization of a new organizational form.
\end{abstract}

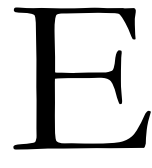

nvironmental sustainability efforts have become widespread throughout the sport industry. Yet individual sport federations, leagues, and teams address environmental sustainability in different ways. One way in which college athletic departments have responded to deepen their environmental commitment is by establishing "green committees" or "green teams." Green teams consist of relevant internal and external stakeholders that can help advance an organization's 
sustainability initiatives (Natural Resources Defense Council, 2013). These committees are voluntary and formal collaborative arrangements between members with varied backgrounds, including campus sustainability, athletics, recreation, transportation, waste management, sponsorship companies, campus facilities, concessionaires, and environmental NGOs. By bringing industry partners and representatives from local government and non-profit environmental organizations together, these committees form complex tri-sector partnerships (Selsky \& Parker, 2005). Thus, they can serve as valuable examples of tri-sector environmental collaborations, the subject of which has been surprisingly absent from existing environmental partnership studies despite the increasing frequency in which these committees are forming (Wassmer, Paquin, \& Sharma, 2014).

Given that sustainable committee members belong to distinct sectorial affiliations and present wide ranges of experience, expertise, power, and motives, it is of paramount interest in this study to provide a better understanding of how such cross-sectoral green teams are formed and how sector boundaries span and then ultimately erode. Thus, the purpose of this study is to examine how organizations, in an effort to respond to environmental concerns, have adapted their structures, processes, and values through transformational partnerships. As part of the study, we endeavor to demonstrate how traditional sector lines are being blurred and innovative hybrid organizations are emerging, thereby shifting traditional ways and expectations of addressing environmental issues.

The contextual focus of our study involves cross-sector social partnerships (CSSPs), a form of collaborative engagement that has received widespread attention in recent years, especially in organization studies (e.g., Clarke \& Fuller, 2010; Cornelius \& Wallace, 2010; Lin, 2014; Selsky \& Parker, 2005, 2010; Townsley, 2014; Wassmer et al., 2014). Selsky and Parker (2005) defined CSSPs as relations that are "formed explicitly to address social issues and causes that actively engage the partners on an ongoing basis" (p. 850). Despite its various terminology, CSSP is considered a subset of cross-sector partnerships and interorganizational relationships whose priority from the outset is to achieve societal outcomes such as improving environmental sustainability, an initiative central to our study (Seitanidi, Koufopoulos, \& Palmer, 2010).

A review of the sport management literature also indicates a gap in understanding CSSPs. Although the examination of cross-sector partnerships in the sport context has yielded several examples (e.g., Babiak, 2009; Babiak \& Thibault, 2009; Dowling, Robinson, \& Washington, 2013), little attention has been afforded to the CSSPs being organized across sport to address environmental concerns, specifically in collegiate sport 
(Babiak \& Trendafilova, 2011; Kellison, Trendafilova, \& McCullough, 2015; Pfahl, 2013; Trendafilova, Nguyen, \& Pfahl, 2014). Environmental sustainability initiatives have been assessed in intercollegiate sport through cross-functional collaborations (Casper, Pfahl, \& McSherry, 2012; Pfahl, 2010; Pfahl, Casper, Trendafilova, McCullough, \& Nguyen, 2015). In addition, most of the literature on sustainabilityrelated partnerships has focused on two types of bisector partnerships, both of which involve the private business sector (Wassmer et al., 2014). Besides the focal involvement of the latter in environmental collaborations, the role of universities has been overlooked in spite of being a critical component for supporting environmental causes. Indeed, the higher education sector may support the capability to generate benefits to civil society, so there is a need to examine this unique social sector more closely when discussing environmental collaborations.

From the few studies that incorporated this sector, the research component of the university was capitalized to achieve environmental goals (Agrawal, 2001; Parker \& Crona, 2012; Steward \& Conway, 1998). Aside from research capabilities, many large public universities have their own sustainability offices that have the duty to carry environmental initiatives. These universities also house prestigious athletic departments that can serve as valuable instruments for engaging various stakeholders in environmental stewardship.
Previous research has demonstrated that there is a working relationship, albeit unbalanced, between college athletic and sustainability offices (Pfahl et al., 2015). However, due to its public visibility, collegiate sports may influence environmentally sustainable practices and act as the champions of the sustainability movement. Thus, the higher education sector possesses strategic resources, capabilities, assets, and influence that can contribute to a CSSP aimed at inducing societal change, especially with regard to environmental issues (Dentoni \& Bitzer, 2015). Additionally, environment-focused CSSPs may serve as a medium through which the perceived academic-athletic ideological gap can be bridged (e.g., Nichols, Corrigan, \& Hardin, 2011). Therefore, in analyzing the tri-sector partnership processes and structures of an innovative collaborative relationship as illustrated by a green committee, this study contributes to both the sport management literature and environmental sustainability partnerships studies.

\section{Theoretical Foundations}

Models of cross-sector relationships have generally been organized into formation, implementation, and outcomes phases (Gray, 1989; Selsky \& Parker, 2005; Siegel, 2010; Wohlstetter, Smith, \& Malloy, 2005). Given that the formation stage usually refers to the motives for initiating partnerships, the first stage focuses on theoretical rationales for partnership 
formation. The subsequent phase in the evolution of CSSPs refers to managerial and operational aspects of partnership implementation since this phase incorporates activities such as "governance, structure, and leadership characteristics, as well as behavioral dynamics such as culture, communication, and relationship development" (Selsky \& Parker, 2005, p. 855). In this phase, partnership members attempt to span sector boundaries by establishing and cultivating transformational collaborative relationships (Austin \& Seitanidi, 2012a; Selsky \& Parker, 2005; Townsley, 2014). In the final phase, such collaborative relationships combined with an aim at achieving societal change lead to the expansion of boundaries such that the emergence of hybrid organizations may be deemed a key intangible result that stems from CSSPs. To illustrate the evolution process of CSSPs, these three stages are discussed in turn below.

\section{Crossing Boundaries: Motives in the Formation of CSSPs}

The identification of preconditions and antecedents of cross-sector collaborations is a critical activity to ensure the effectiveness of CSSPs. This activity represents the foundations of the partnership upon which subsequent collaborative engagement and arrangements will occur. Indeed, it is essential to clearly determine motives to join CSSPs prior to launching cross-sector projects. Among the theoretical perspectives that have commonly been referenced in the management literature as motivations for partnership formation (Barringer \& Harrison, 2000; Ireland, Hitt, \& Vaidyanath, 2002; Siegel, 2010), we found four types of motivations for cross-sector collaborations supporting social causes: economic, leverage, legitimacy, and central to this study, societal-related motives. Although each of these perspectives was proven to be useful in explaining the reasons for relationship formation, we largely focus on the societal-related motives in this review and start by presenting a brief overview of the other three motives. (For a complete review of those motives, see Barringer \& Harrison, 2000.)

Non-profit sport organizations have engaged in strategic alliances with organizations in the private, public, or commercial sectors for economic-related motives in order to offset increased organizational risks (Babiak, 2007). This belief of dependency triggers the need to develop cross-sector relationships with stakeholders who can provide scarce and necessary resources vital to the success of the organization (Babiak \& Thibault, 2009; Pfeffer \& Salancik, 1978). As mentioned by Babiak (2007), such relationships are established to acquire expertise, secure access to key resources, and gain control over turbulent settings. Amateur sport organizations also follow suit with regards to implementing environmental sustainability campaigns through various partnerships (McCullough, Trendafilova, \& Picariello, 2016). Furthermore, leverage- 
related motives have proven to be useful in conceptually presenting the process of strategic planning for cross-functional environmental sustainability teams working in the sport and recreation industry (Babiak, 2007; Babiak \& Thibault, 2009; Pfahl, 2010). Indeed, those organizations seek to acquire complementary and distinct resources in order to be more effective and competitive as a whole (Babiak \& Thibault, 2009). For instance, partnering with nonprofit groups for environmental initiatives enables sport organizations to have access to their expertise and network of supporters (Babiak \& Trendafilova, 2011). The 2018 Special Olympics USA Summer Games in Seattle can also serve as a practical example of an amateur sporting event seeking to improve its environmental performance by partnering with corporate sponsors, vendors, and volunteers, among others, in order to combine each of these groups' existing idiosyncratic and complementary resources (visit specialolympicsusagames.org). Finally, motives to address institutional pressures incite organizations to get involved with partnerships that will make them appear as socially and environmentally responsible by applying the concept of institutional mimetic isomorphism (DiMaggio \& Powell, 1983; McCullough, Pfahl, \& Nguyen, 2016). Those legitimacy-related motives can facilitate public image enhancement and conformity with social norms, as evidenced by sport organizations engaged in environmentally focused initiatives (Babiak \& Trendafilova, 2011).

Societal-related motives have been mostly explained through stakeholder theory. Given that organizations are part of an intertwined stakeholder network, they are conscious that any of their decisions and actions may affect their strategic relationships with other social actors in that network, so a sense of responsibility and mutuality toward their stakeholders is of primary concern in stakeholder theory. With its emphasis on societal problems and sectoral interdependence, the focus of these partnerships is based on ethical obligations in which collective interests rather than selfinterests are to be served (Sartore-Baldwin, McCullough, \& Quatman-Yates, 2017). These strategic alliances enable the development of objective congruence among social actors of the network, particularly with respect to environmental and social endeavors (Doh \& Guay, 2006; Sartore-Baldwin \& McCullough, in press; Rod \& Paliwoda, 2003). As a result, Siegel (2010) suggested that "to claim citizenship in a cause is to redraw organizational boundaries in such a way that the cause itself becomes the central organizing principle" (p. 41); hence, the desire to be a responsible citizen encourages societal initiatives.

As Babiak $(2007,2009)$ found in her line of research, there are helpful aspects that help draw and sustain the connection between members of a CSSP. She found that a personal connection to the cause or 
individuals increased trust and strengthened the network of individuals and organizations in the CSSP. In particular, non-profit sport organizations can draw an increased affinity and connection among stakeholders that are unique across other commercial industries. This approach is particularly important for amateur sport organizations that may be considerably limited in human and financial resources and who can leverage the goodwill their organization has in the community to partner with outside organizations to achieve their goals (Misener \& Doherty, 2013).

In this first phase, it is critical to locate crossing points in sectoral boundaries then find reciprocal transformative intentions (Seitanidi et al., 2010). The importance of such a phase was demonstrated in the professional and amateur sport settings (Gerke, Babiak, Dickson, \& Desbordes, 2017). Once the motives and suitability for crossing traditional sector boundaries are clearly recognized, implementing crosssector partnerships entails building on this momentum and needs to be examined to better understand how CSSPs develop over time. According to Austin and Seitanidi (2012b), in this second stage, transformative processes that shift sector boundaries are established, calling for the need to examine the evolutionary dynamics of CSSPs' implementation in the next section.

\section{Bridging Boundaries: Collaborative Relationships}

Whether the formation of CSSPs is justified by synergistic abilities of achieving more with less or leveraging resources and reducing redundancy, such partnerships are championed by those who have the ability to bridge sector boundaries. These champions, sometimes referred as "boundary spanners" (Le Ber \& Branzei, 2010), "boundary spanning agents" (Marchington \& Vincent, 2004), or "boundary crossers" (Hora \& Millar, 2011), act on the behalf of their organizations and advocate for the development of powerful organizational collaborations such as CSSPs to undertake initiatives that create public value (Townsley, 2014). Thus, these champions carry bridging functions in order to connect members from distinct sectorial affiliations and nurture the launch of innovative collaborations sharing resources and mutual goals (Manning \& Roessler, 2014).

Negotiating agreements are necessary for partnerships to prosper. Although champions are not necessarily representatives of the top leadership team, mid-level managers may play the champion's role (Schroeder, 1999). Their formal or informal leadership role will help involved constituents unlearn traditional organizational and sector-based functions to facilitate their engagement toward implementing CSSPs. Despite the possible lack of formal sources of power, champions strongly influence the direction and manage 
structures, processes, and outcomes of the collaborative partnership. Instead of being based on traditional leadership models with an emphasis on hierarchical structures, a CSSP's leadership structure highlights facilitative and relational processes (Townsley, 2014).

In the context of our study-amateur sport in general and college athletics specifically-a green committee provides a frame for a formal collaborative arrangement with a joint decision-making process. Committee members correspond to environmental champions from various sectors with competing perspectives and expectations but with complementary needs and resources whose mission is to attain environmental excellence through sustained collaborative partnerships across sectors. Members of these committees carry boundary spanning roles as they operate at the intersection of sector boundaries and intend to set up bridges between sectors to establish interdependent partnerships with mutual goals. Although the complexity of interactions is heightened by the crosssector aspect of the relationships with competing power and diverse leadership styles, these champions-highly committed to the CSSP's goals-reunite under this committee in an effort to smoothly run this complex partnership and monitor its progress over time to ensure the achievement of the compatible goals (Rondinelli \& London, 2003; Wohlstetter et al., 2005).
In addition to the presence of champions, organizational compatibility is critical and may be established by discerning broad linked interests and shared issues, and integrating central missions, values, and strategies to help reconcile differences, align intentions and expectations, and deepen trust between partners (Gray, 1989; Seitanidi et al., 2010; Selsky \& Parker, 2010). Recognizing congruency between organizations and developing a common agenda require an effort from each champion and partner to mutually understand and appreciate each other's differences. To evolve into a transformational collaboration, organizational fit between partners must be determined in order to capitalize on distinctive competencies and complementary resources that are exchanged conjointly. This mutual resource dependency will contribute to the creation of synergistic partnerships. Indeed, the primary premise of transformational collaborations is to combine partners' knowledge, resources, and expertise to achieve more together than they could have alone (Austin \& Seitanidi, 2012a). Tangible and intangible assets from different sectors are combined into a unique amalgamation of resources that will help generate benefits to partners and create innovative solutions to societal problems that could not have been accomplished by a single sector alone (Austin \& Seitanidi, 2012b; Bryson, Crosby, \& Stone, 2006; Nelson \& Zadek, 2000). Under this premise, frequent innovations 
such as fundamental changes and superior results are likely to be advanced.

In deciding to pursue a transformational engagement, CSSP champions deliberately recalibrate their roles to coordinate societalfocused initiatives with the belief that such effort is imperative to create fundamental changes and address societal problems. In addition, these champions facilitate the shifts in sector boundaries and in organizational roles. Thus, transformational collaborations' effects may "change each organization and its people in profound, structural, and irreversible ways" (Austin \& Seitanidi, 2012a, p. 744). After developing transformational collaborative relationships, champions need to assess the outcomes of CSSPs, as discussed further in the next section.

\section{Blurring Boundaries: Societal Change as a CSSP Outcome}

Following the implementation phase and the execution of CSSP-related projects, an evaluation is necessary to ensure progress is being made toward solving shared problems. Any discrepancies with planned outcomes require improvements or changes to the second phase, emphasizing the iterative and adaptive nature of CSSPs (Murphy, Perrot, \& Rivera-Santos, 2012; Wohlstetter et al., 2005). Although organizational benefits and tangible results are important, the top priority of these transformational CSSPs involve societal betterment, and the evaluation phase enables the examination of such impact.
Another intangible outcome entails the emergence of a pioneering "hybrid organization" caused by the expansion of sector boundaries (Boyd, Henning, Reyna, Wang, \& Welch, 2009; Selsky \& Parker, 2010). Selsky and Parker (2005) suggested that CSSPs have the potential to evolve into a collaborative arrangement in which sector boundaries are blurred. This potential must be accompanied with transformational collaborative relationships between partners and an aim toward remedying complex public issues to enable the discovery and expansion of new frontiers. From transcending boundaries to blurring them, this evolving and interactive network of people discovers ways to combine distinct and complementary resources and unify perspectives to create synergistic solutions that go beyond each of their own sectors' limited competencies and vision. As a result, these partnerships may create more public value together than what individual sectors could have achieved separately (Gray, 1989; Selsky \& Parker, 2005); hence, they provide a means to alleviate and respond to society's most pressing concerns (Boyd et al., 2009; Getha-Taylor, 2012).

Contemporary societal problems are so large and complex that they cannot be solved by any private, nonprofit, or public actor alone; these actors are obligated to transcend traditional sector boundaries in order to address society's grand challenges adequately (Selsky \& Parker, 2010). Since champions and partners met together primarily to achieve collective changes at 
the societal level rather than to focus uniquely on their own organizational selfinterests, they engage in transformational collaborations that enable a shift in the three sectors' identities and roles by fusing them into a hybrid organization. As a result, evolving into transformational, collaborative relationships may help not only to span boundaries but also eventually merge sectors into one new entity that is governed by merged authorities and operated by merged capabilities and activities, resulting in the blurring of traditional boundaries between sectors (Bryson et al., 2006). This blurring process leads to promising pathways for aspirational and transformative societal changes, which are the main focus of transformational collaborations. For instance, green committees may aspire to make transformative societal changes by improving environmental standards, fostering recycling, and lessening pollution. Therefore, in an effort to address societal needs such as environmental protection, partners engaging into a transformational CSSP may not only bridge sector boundaries but also blur them by replacing the old and narrow sector mindsets with an innovative, transformative, and "missiondriven" (Boyd et al., 2009) organizational form.

In the section above, we highlight the benefits of an effective and synergistic CSSP. However, the formation of these partnerships can be a complicated process, as individuals and departments may enter the CSSP with diverse (and sometimes divergent) goals and strategies. These differences may be especially pronounced in large partnerships that span commercial, nonprofit, and government sectors. In this study, we examine the process of forming and implementing a CSSP with the goal of advancing pro-environmental initiatives in a large intercollegiate athletic department. As demonstrated below, this setting presents several unique challenges; the identification of these challenges can advance the function of CSSPs in amateur sport and assist sport organizations seeking to advance their own environmental sustainability efforts.

\section{Method}

The unique placement of the green committee and its direct stakeholders makes this case particularly interesting. In previous studies, researchers have examined CSSPs in various contexts including local sport (Babiak, 2007; Babiak \& Thibault, 2009), major sporting events (Meenaghan, 1998), and professional sport (Kihl, Tainsky, Babiak, \& Bang, 2014). However, little consideration has been given to CSSPs in collegiate sport, in general, or how college athletic departments achieve sustainability objectives by leveraging CSSPs, specifically. As a result of this lack of research, we sought to evaluate a CSSP established by a college athletic department renowned for its sustainability achievements. While this specific context and objective of the CSSP have not been examined before, it is 
nevertheless important as more sport organizations begin to increase their commitment to environmental sustainability (Kellison \& McCullough, 2017; McCullough \& Kellison, 2017; McCullough et al., 2016). Further, amateur sport organizations typically encounter financial limitations that require them to seek outside assistance to achieve organizational goals (e.g., environmental initiatives; Babiak \& Thibault, 2009). To this end, we employed a case-study qualitative methodology, which has been commonly used by Babiak and others to research new areas of inquiry related to CSSPs.

Specifically, we examined the evolution of an environmental-focused CSSP through semi-structured interviews with members of a sustainability committee (i.e., Green Team) centrally located in a university athletic department in the western United States. The Green Team was formed in 2010 as one of the earliest and well-known sustainability committees across all levels of sport. As a CSSP, the Green Team is made up of more than 20 individuals (including students and student-athletes, university personnel, and industry partners) representing a wide range of departments, including business and finance, operations, marketing, grounds and facilities, ticketing, university sustainability, waste management, and concessions. More specific information on the participants is provided below.

\section{Participants}

Interviews were conducted with current members of the green committee organized by the athletics department at the university. In total, 11 interviews were conducted over the course of two weeks in March 2016, which included five Athletics representatives, one student-athlete, and personnel from non-Athletics departments including a concessionaire, three members from the university Office of Sustainability, and an employee from the Waste Management department. Table 1 contains basic information for the participants interviewed for this study including each participant's pseudonym, years served on the Green Team, role at the university, and student-professional status.

It should be mentioned that there were members of the Green Team missing from the participant roster, most notably, representatives from the athletic department's sponsorship and marketing departments. These non-participating representatives explicitly stated that they did not want to be interviewed for the study. Further, we were predominately dependent on athletic department connections of the members on the committee. In particular, the Green Team's coordinator and other members of the committee assisted with arranging interviews and meetings. The coordinator of the committee was able to speak to these two areas despite the nonparticipation of the individuals. This aspect will be discussed further below. 


\section{Procedures}

Following Cunningham (2009) and as originally outlined by Alderfer (1980), we employed an organizational diagnosis approach to the study. This approach is "a process based on behavioral science theory for publically entering a human system, collecting valid data about human experiences with that system, and feeding that information back to promote increased understanding of the system by its members" (Alderfer, 1980, p. 459). We deemed this approach appropriate since sustainability teams are rather limited in sport organizations in general and college athletic departments specifically (Kellison \& McCullough, 2016). The byproduct of this approach allows a broad understanding, or group interpretation, of organizational processes by the members of the committee. This approach also allows for a deeper understanding of how the green committee has performed by evaluating its past, current, and planned initiatives.

Semi-structured interviews with each participant ranged from 35-70 minutes. The interview guide specifically examined how the CSSP (i.e., Green Team) was formed, implemented, and evaluated. Interviews were recorded with permission of the participants and then transcribed verbatim for analysis.

\section{Analysis of Empirical Material}

We followed a constructivist (interpretivist) paradigm, which allows the empirical material to be analyzed into codes based on the themes of a theoretical framework (see Ponterotto, 2005); this analytic approach has been used in other qualitative studies within the academy (Cunningham, 2009; McCullough, 2013). This method of coding is commonly referred to as an "a priori, content-specific scheme" whereby codes emerge through careful and rigorous study of the issue and the theoretical interests that guide the inquest (Schwandt, 2007). Thus, the empirical material was analyzed and coded according to themes informed by the guiding theory (i.e., cross-sector relationships; Gray, 1989; Selsky \& Parker, 2005; Siegel, 2010; Wohlstetter et al., 2005).

Several steps were taken to improve the credibility and trustworthiness of the empirical material. To improve the study's internal trustworthiness, we employed methods triangulation. That is, testimony from Green Team members was compared with internal communications, websites (i.e., Athletics, Office of Sustainability, Waste Management), and press releases related to the athletic department's sustainability efforts. These documents were consistent with the testimony from the participants' interviews. Additionally, two peer debriefers (neither of whom were involved with the study but were familiar with qualitative methodology) audited the research process. As part of the audit, they reviewed the codes, themes, and interpretations of the empirical material. Lastly, a summative report and presentation were given to the green committee to seek their thoughts on 
the interpretations and findings of the study of inquiry.

\section{Results and Discussion}

In the following section, we discuss the various themes that emerged from the interviews of the Green Team members. These themes include: formation and tasks of the Green Team, transition and growing pains, and boundary blurring. As the results will show, the initial formation of the Green Team was tasked to focus on a specific project (i.e., renovation of the football stadium) and to achieve Leadership in Energy and Environmental Design (LEED) Silver certification. A bulk of the energy and accomplishments were driven by upper management (e.g., Athletic Director, University President), who made lofty goals more easily attainable. The committee experienced growing pains as it struggled to find its new identity and tasks after the culminating stadium project and concomitant support from upper management dissipated. However, as new initiatives were introduced, new committee members joined, requiring more openness and adaptability on behalf of Athletics. That is, the athletic department members on the Green Team were not comfortable letting the coordination and leadership of specific initiatives go to outside members (e.g., Campus Recycling).

\section{Formation and Tasks of the Green} Team

To determine the underlying motives for commitee formation and each member's involvement with the Green Team, we asked participants to describe how they became involved with the Green Team and their general thoughts on its mission. Indicating societal-related motives, most participants mentioned that the university as a whole had placed a strong priority on environmental sustainability. As an extension of that priority, the athletic department was responding in kind to do its part to fulfill the university's commitment "to be sustainable by 2025," as noted by Tim, a senior-level participant: "That is a core value of the university. When you have that core value of the university, it is easier for Athletics to implement environmental sustainability. The support from upper campus has been great." The encouragement from the university's upper administration and specifically from the campus Office of Sustainability was viewed by Athletics and non-Athletics Green Team members as an impetus to the Green Team, a notion supported by previous research. For instance, following the tenet of upper echelon theory, McCullough and Cunningham (2010) posited that the degree to which sustainability initiatives would be implemented is greatly dependent on the attitudes of upper administration (Hambrick \& Mason, 1984).

Further supporting the societal-related motive, the organizational culture and 
positive attitudes toward environmental sustainability on campus clearly influenced the perception and attitudes of the members of the Green Team. In fact, the Green Team was commissioned by the Athletic Director because of a planned major renovation of the football stadium. As noted by Joan, the original and current chair of the Green Team, the stadium renovation drove conversation in the early days of the committee: "The seed that started it all was the stadium construction project, the talk about...certification, what that meant, and who knew about it." The renovation was a multi-hundred-million-dollar project that prioritized environmental aspects into the construction and operation of the facility including LEED certification and a dualstream waste management system (i.e., diverting all waste away from landfills via composting and recycling). The renovation project would serve as the launching point for the athletic department to implement a sustainability program. However, realizing the limitations of the athletic department's Executive Staff and consistent with leveraging-related themes discussed previously, it was noted that the Athletic Director asked if anyone in the department had knowledge or interest in spearheading the launch of their sustainability program. As members of the athletic department began to defer to outside experts, the need to include individuals outside of Athletics became clearer. This perspective allowed the expertise of new partnerships to inform the athletic department about how they could meet their sustainability goals, thereby spanning the boundaries of the athletic department and its support system.

As a result, architectural partners and campus staff were able to lend their expertise so that the stadium renovation achieved LEED Silver certification. Further, members of the Green Team representing the university's Office of Sustainability had specific expertise in communications, which helped to "tell the success stories of the athletic department's sustainability efforts." One such press release produced by a committee member promoted the project's forward-thinking design:

The project's approach to sustainability looked past the basics of water and energy conservation to enhance infrastructure, reduce the building's impact on the surrounding environment and provide a platform that has allowed [the university] to promote sustainability to its stakeholders, students, and fans.

While the exposure that various Green Team members were able to provide for the renovation project, this publicity highlights the various aspects and components that were considered and integrated into the project by the Green Team.

When questioned further, Joan indicated that economic- and leveragerelated themes were also considered when selecting the first members of the committee. She mentioned the recruitment of architects, athletic department staff, nonathletic department staff, and off-campus 
vendors that served the athletic

department's sustainability goals. As Joan noted, the Green Team was created "with the task of analyzing and putting in place practices for the reopening of the stadium." In order to achieve these goals, it was necessary to expand the boundaries beyond the athletic department staff and avail the committee to the various resources on campus. As previously noted, university campuses have resources that are not readily accessible to other sport organizations. Expanding the partnership to include these unique resources (e.g., recycling, waste management, sustainability, faculty, students) can also increase the capabilities and capacity for the CSSP to achieve its goals because of the unique background of these specific stakeholders (Babiak, 2007).

By design, the organization of the first Green Team included all nine major departments within Athletics. Several reasons explained this inclusiveness. First, as a number of participants indicated in interviews, it was necessary to have the support of the entire athletic department to ensure the permutation of a sustainabilityminded culture in the athletic department and a general awareness of what the Green Team was doing. Two senior-level members of the Green Team mentioned that because of the wide base and involvement of all departments, there was at least one person from each department championing sustainability in her or his respective departments. It was deemed necessary by the coordinator of the Green Team that all nine departments be represented on the committee, including athletic department partners (e.g., concessionaires, sponsorship sales company), campus waste management, and sustainability. Mark, a mid-level athletic ticketing office employee, stressed the importance of involving various departments because it was the "best way to get the message out on the things that everyone can do to help." Previous research has noted the challenges athletic departments face when attempting to play an active role in promoting and integrating environmental sustainability into their daily operations (Pfahl et al., 2015). Pfahl and colleagues (2015) noted that sustainability offices are generally the cause for athletic departments to start implementing environmental sustainability. However, in the case of this study, roles were reversed: the on-campus Office of Sustainability served in a supportive role to the athletic department and its initiatives.

The primary reasoning behind the inclusion of various departments was to promote and spread a sustainable organizational culture. However, this desire to include all departments also served another purpose. The second intention for widespread involvement on the committee was to have the range of expertise on the committee, which doubled to increase the buy-in and cooperation from the various departments. The range of athletic department staff included personnel from marketing, sponsorship, concessions, facilities, and operations. Specific to the 
organizational buy-in, Joan noted, "When you're talking about stadium operations, and changing the culture...everyone that is going to work on that event has to be there. Everyone has input on what's going to work and what would not." While the involvement of all nine major departments allowed for additional buy-in, some departments were not directly related to the bulk of work needed to ensure various stages of environmental sustainability. McCullough et al. (2016) described sport organizations in various stages of their progression and sophistication to integrate environmental sustainability into their daily operations. Similarly, the athletic department and Green Team examined in this study has proceeded through various stages such that while some departments represented by committee members may have valuable input, others may not bring much expertise to the table. This constant involvement of nonessential departments or staff seemingly decreased the attitudes and perceptions of the committee's efficacy by some members.

The second reason for the broad inclusion of all intra-Athletics departments in the Green Team was to garner support for sustainability initiatives across the athletic department. The successful renovation of the football stadium and the resulting accolades it received for its proenvironmental design bolstered the momentum of the Green Team, which was trying to generate excitement within Athletics in order to encourage a deeper commitment from all members of the department. As Joan noted, while not all departments may have had direct involvement with sustainability initiatives on a daily basis (i.e., ticketing and marketing), it was nevertheless important to have their departments represented on the committee. She argued that by having each department represented, "There was now someone in each Department of Athletics who could advocate for Athletics' sustainability initiatives." Still, as noted by some Green Team members of the team, an individual's membership in the team does not automatically translate to involvement with tasks and projects. In light of the perceived lack of contribution from some members, Joan expressed her intention to slowly acclimate each department by empowering individuals working toward the athletic department's sustainability efforts: "Everyone that is going to work on that event has to be there. Everyone has input on what's going to work and what would not." As noted earlier, valuing the expertise of each department with regard to its possible contributions to the committee can advance their respective interests in the objectives of the CSSPs. The inclusion of all intra-athletic department units expands Babiak's (2007) research by suggesting that expansion of included stakeholders is necessary to develop an organizational culture that fosters awareness and acceptance of the committee's sustainability efforts. 
During the formative period of the Green Team, committee members were singularly focused on the football renovation project. After the successful completion of that major project, the committee began working broadly to implement environmental sustainability across the athletic department's operations. During this transition phase, the Green Team underwent several changes, including increased autonomy, reorganization, and changes to membership. Additionally, the team began working on multiple, small-scale projects that necessitated the formation of subcommittees. As discussed in the next section, this period was marked by Green Team members operating at the intersection of sector boundaries and establishing intersector partnerships with mutual goals.

\section{Transition and Growing Pains}

During the initial task of the Green Team, there were considerable amounts of funding and attention from the athletic department's executive staff. These resources afforded the Green Team more credibility and legitimacy. However, after the stadium renovation project was completed, Athletics administrators became less involved as the Green Team repositioned itself toward a new, broader goal: to integrate environmental sustainability across the athletic department from its organizational culture to its daily operations. As noted by several interviewees, this lack of support or involvement had inadvertently undermined the efforts of the Green Team as the committee tried to inculcate each department within Athletics to adopt an environmental sustainability mindset. For example, Steve, a senior Athletics Facilities manager, argued, "Even here, football refuses to put compost bins in the football office." The lack of involvement from various departments within Athletics ultimately created a barrier for even the senior staff on the Green Team to connect with the executive staff or Athletic Director to encourage widespread compliance. This barrier increased the Green Team's reliance on non-Athletics members of the committee to help advance its sustainability programs. As Babiak (2009) noted, these pressures may lead sport managers to seek new partnerships to help achieve complex organizational goals. However, the goals as stated by the Green Team leader demonstrate a desire for complete buy-in from all intra-department units beyond the success of various game day or facility upgrade projects.

To this end, smaller initiatives were delegated to the Green Team, while larger projects-generally with a larger cost savings or return on investment-were overseen by Athletics administrators. For example, the Green Team proposed and priced out a project to install LED lighting throughout several facilities and all athletic department offices. The cost of the project was nearly $\$ 1$ million, but once the athletic department's executive staff approved the project, the Green Team relinquished 
oversight of the project to upper-level administration.

On the other hand, some major projects have been left under the Green Team's authority. For example, waste management and diversion rates remain tremendously important to the Green Team. In-stadium recovery rates have plateaued between 75 $80 \%$, but there is no organized waste recovery system in the tailgate lots. Tailgating was characterized as "the wild west of waste recovery" by Melissa, the Green Team's Facilities representative. McCullough (2013) noted the distinct differences between in-stadium and parking lot experiences with waste management systems (e.g., landfill, recycling, composting). These differences were in large part related to the unique jurisdictions of each campus department (i.e., Athletics managed in-stadium waste, while Facilities or Transportation and Parking handled parking and tailgating lots). While tailgating waste management systems would have a financial return and environmental benefit, these sustainability programs would require the coordination of a large number of departments and sectors. Therefore, Athletics administrators have left waste management to the Green Team and its members.

Champions. There was unanimous agreement among participants that the leader of the Green Team was Joan, the original and current chair of the committee. Described by others as an individual deeply passionate about environmental sustainability, in her own interview, Joan expressed concern that her responsibilities on the Green Team had led to job enlargement- the expansion of workrelated duties. In addition to serving as Green Team chair, Joan is a senior administrator in the athletic department. Thus, she stressed the need for more Green Team members to adopt leadership roles. Such roles, she argued, required not just expertise, but also passion:

I think that you got to have people that are passionate about it and you have to seek those people out. It is really tough to have any program-it's tough to keep it going without that energy. That is where our partnership with campus is critical because of their passion. Through her passion and notoriety around the athletic department and on campus, Joan has been able to involve various campus stakeholders on the committee, primarily from waste management and campus sustainability. As a "boundary spanner" (Le Ber \& Branzei, 2010), she has sought partnerships with other stakeholders to forward the Green Team's successes into the next phase beyond the stadium renovation. As noted earlier, these connections bridge specific functions or expertise that help attain mutual goals (Manning \& Roessler, 2014). However, based on Joan's testimony, the Green Team in its current form may not be efficiently functioning in this role.

All athletic department participants noted that the committee chair, Joan, was 
the driving force of the committee. When it came to idea generation, committee

members from Athletics and the university's Office of Sustainability predominately identified Joan as the individual who would identify tasks and deploy subcommittees to address specific aspects. In fact, the Green Team's four subcommittees-Branding and Marketing, Data Collection (Energy/Water), Celebrating Success, and Events-were created by Joan. Each member on the Green Team is assigned to a respective subcommittee, and these subcommittees are encouraged to meet at least once between the quarterly Green Team meetings.

However, because of the lack of time Joan has to dedicate to directing the subcommittees, several committee members acknowledged that subcommittee meetings were not taken seriously. For example, Nicole, the Green Team's student-athlete representative, quipped, "I don't even know if I went to the last subcommittee meeting." The intended purpose of the subcommittee is to pair members with similar job responsibilities to support the Green Team's efforts in one form or another, but because environmental sustainability is an ongoing process, it is necessary for constant progression. However, Frisby, Thubault, and Kikulis (2004) demonstrated sport administrators do not have the experience or expertise to manage these complex partnerships. This finding is also supported by other researchers who examined the organization and leadership of organizational partnerships due to the difficulties and responsibilities that fall upon the leader (i.e., champion) to maintain the cohesion and direction of the group (Babiak, 2007, 2009; Babiak \& Thibault, 2008). One way to boost cohesion is through these ancillary meetings. In effect, these meetings could serve as ways to advance the overall committee's progress. For example, Patrick in the Office of Sustainability said their goal was to "strengthen the relationship with [Athletics] a little bit and to provide even more support" in order to fulfill the university's overall sustainability goals.

\section{Mutual goals, different approaches.}

A boundary spanner who effects change like the Green Team chair brings various stakeholders together to achieve specific goals. Representatives from two nonAthletics units-the Office of Sustainability and Waste Management-expressed the mutual desire to promote and deepen the university's commitment to environmental sustainability. Despite this common goal, the two departments take different approaches to their roles on the Green Team: while the Office of Sustainability serves a supportive role, Waste Management endeavors to exert more influence.

The Office of Sustainability's Green Team members mentioned how their role on the committee was "supportive," "to provide recommendations," or "to help with specific ideas." These members understood that environmental sustainability was a relatively new concept to most personnel in Athletics, so they wanted 
to build momentum slowly within the department to ensure initial success. Ronan, most senior among Green Team members from the Office of Sustainability, said, "I don't feel like my role is so much to come in and try to... be a dominant voice but to kind of listen-to see what they're talking about and offer suggestions where appropriate." This approach has encouraged and informed the Green Team on establishing new relationships throughout campus, sharing ideas, and avoiding mistakes made by other departments on campus. This bridge with the Office of Sustainability has linked the athletic department with university-wide goals. As discussed by several interviewees and in the literature, university athletic departments are often perceived to operate independently from the university, leading to "dual organizational identities of institutions" (Buer, 2009, p. 110). However, the formation of the Green Team-which linked Athletics to the broad sustainability goals of the university-has provided a medium through which university and Athletics personnel can collaborate and work toward a common goal. While the Office of Sustainability maintains sharply defined roles, other members desire boundary blurring of roles through deeper collaboration.

For instance, the Waste Management department wants to take a more active role on the Green Team, particularly when it comes to addressing one of the Green Team's main responsibilities: game day diversion rates. Emily, the lone member on the Green Team from the university's Waste Management department, discussed several shortcomings with the current procedures to increase diversion rates and referenced her expertise and that of others on campus (i.e., behavioral scientists) who could help increase waste recovery rates. Despite having the knowledge and rich experience to address problems with the current system, Emily described her hesitance to intervene: "I don't want to be always harping on certain things - so I go along." Here, Emily channels a tension several others acknowledged during interviews: although each member of the Green Team brought her or his own expertise to the table, there was a reluctance to engage beyond a supportive capacity. This timidity is especially meaningful considering Waste Management's expressed desire to be more involved with the Green Team. Moreover, Emily described her willingness to oversee waste recovery across all game day venues, noting that Waste Management would be "more than willing to provide resources to improve programs and recovery rates." As discussed below, there may be several reasons behind some Green Team members' disengagement in committee projects. This disconnect is common in partnerships that do not properly engage the members with specific tasks and ill-defined roles on the committee (Babiak \& Thibault, 2009). As such, uninterested or disconnected members will withdraw from their involvement, possibly undermining the 
committee's goals. Nevertheless, it is clear that various members of the Green Team, particularly those outside of Athletics, are ready to work in a greater capacity to forward the committee's sustainability programs but are reluctant to take initiative.

\section{A Prescription for Balanced Boundary Blurring}

On the surface, the Green Team exemplifies a hybrid organization; because it comprises both university and Athletics representatives but operates largely autonomously, its membership consists of representatives with varied backgrounds and expertise. Still, each members' responsibility to the Green Team is secondary to their primary roles on campus (i.e., their professional and/or academic obligations). When it comes to boundary blurring-a process marked by unified perspectives and solutions that transcend individual competencies - it is clear that some individuals feel integral to the committee, while others have yet to be utilized fully.

If the Green Team is to move forward, it will become necessary for Athletics members to more heavily rely on its nonAthletics committee members. The initial sustainability programs that the Green Team implemented have been rather unobtrusive to employees and spectators. That is, the initiatives selected (i.e., green building design, two-stream waste management system, LED lights, electric automation systems) do not require much active participation on behalf of employees or fans to behave in a more sustainable manner. For example, the waste management protocol has only two options - recycle or compost - and if fans do not dispose of their waste appropriately, it is caught during the postgame sorting of all waste. While projects such as this are relatively unobtrusive, they require substantial investment and infrastructure to support. As a result, the proverbial low hanging fruits have been picked and it is necessary for the university, Athletics, and the Green Team to deepen their commitment and increase the sophistication of their sustainability programming. For example, Samantha, the concessionaire contact, discussed the exorbitant amounts of food waste after football games:

The [athletic department says], "Oh, we're having 50,000 [fans in attendance]," and we have 40,000. We made enough food to cover 50,000 so now we have that extra 10,000 people worth of food. So... if we could figure out that science a little better that would be my number one concern to see less food waste on our end.

Specifically, she desired deeper sophistication on predicting how many spectators would attend each game based on specific variables in order to prepare the appropriate amount of food and ultimately reduce the amount of total waste (i.e., compost).

While most participants acknowledged both the university's overall commitment to environmental sustainability and Athletics' 
efforts to be sustainable, they also emphasized the fact that there was more work to be done. As discussed previously, the involvement of multiple departments within Athletics - while well intentionedmay have been counterproductive. The inclusion of each department in Athletics was designed to promote acceptance of the athletic department's orientation toward environmental sustainability; however, this emphasis led to a disproportionate number of Athletics representatives on the Green Team. Thus, non-Athletics committee members may feel like outsiders working for Athletics. Indeed, most of the committee members mentioned they do not take a proactive step to introduce new initiatives, but when asked during interviews about what initiatives they would like to implement, they were not short on ideas. Thus, non-Athletics members have been unintentionally undervalued, and as a result, the CSSP has not fully realized its leveragerelated potential.

McCullough and colleagues (2016) argued that as sport organizations deepen their commitment to sustainability initiatives, the sophistication and coordination of these efforts must increase as well. Green Team members interviewed in this study expressed a strong understanding of this need by pointing to increasingly technical projects such as finetuning recovery rates in the stadium, better addressing waste management strategies in tailgate areas, reducing water consumption in athletic facilities, and addressing fan transportation. Even though athletic department staff members are the main drivers of the various initiatives, the success of intermediate goals (e.g., fan engagement, recovery rates, sustainability transportation choices) are best addressed by non-Athletics members. As mentioned above, for example, the Waste Management department sees much more potential in the recovery rates in and out of the football stadium. Further, Samantha, the concessionaire, conveyed a desire to deepen their involvement to meet her company's sustainability objective to solve the issue of food waste by deepening her "relationship with the client to let them know that this is a warning to us as a business. We are committed to finding ways to create less waste to push the issue." It appears that she, like other outside members, wants to further blur existing boundaries in order to mutually meet sustainability goals. There is a growing necessity to allow non-Athletics committee members to take a larger role in the future direction of the Green Team. However, in order for all Green Team members to fully engage in the CSSP, the committee's chair and fellow Athletics representatives must create an environment that penetrates the perceived fortress common in athletic departments (cf. Buer, 2009) by blurring the boundaries of the athletic department to meet the university's sustainability goals.

When each member was asked specifically what three initiatives they would like to see the Green Team address, they 
predominately listed: increasing diversion rates, addressing tailgating, and an initiative related to their specific position on campus. A non-Athletics member of the Green Team suggested that the committee be restructured to address the sustainability initiatives that they wanted to address. That is, instead of being configured like an athletic department (i.e., Marketing and Promotions, Data Collection, Celebrating Success, and Events), it should be structured around specific initiative categories (e.g., waste management, electricity, water, human behavior). Before these changes can occur, however, more alliances must be given to the Chair and specific content experts on the Green Team.

\section{Conclusion}

The academic mission of institutions of higher learning is sometimes at odds with the athletic mission of their collegiate athletic departments. For this reason, universities are often considered dualidentity organizations. It is clear that environmental sustainability-while a priority at a growing number of institutions-is not the primary focus across all campuses. Still, because CSSPs like the Green Team operate autonomously with one overarching goal (i.e., advancing sustainability initiatives at the university and within Athletics), it can bridge the academic-athletic ideological gap and orient all parties toward a pro-environmental mission. As demonstrated above, however, leadership style and the efficacy of its members can limit the potential of a CSSP. In this study, some members of the Green Team had experienced clear shifts in their work responsibilities and organizational commitments (i.e., blurring boundaries), while others felt that their talents were left largely untapped because of the Green Team's placement within the athletic department.

While we suspect that much of the reason behind the uneven organizational blurring was the result of the Green Team's Athletics-focused orientation, additional research would yield further insight. For example, the Green Team consisted of individuals with varying professional ranks, years of service with the committee and the university, and environmental expertise. These dynamics may have led some members to be assertive while others remained passive. Furthermore, it remains unclear the extent to which turnover among committee members hindered collaboration in the Green Team. Particularly related to student members, the cyclical nature of the university made committee membership relatively unstable.

This study builds on the theoretical development on transformational CSSPs by providing a better understanding of the key enablers and indicators that permit the development of transformational collaborative relationships. We also responded to a need to examine the development of CSSPs by providing the analysis of an in-depth case study with a 
retrospective inquiry to capture the evolutionary dynamics of a complex collaborative arrangement (Kihl et al., 2014; Selsky \& Parker, 2005).

Since sport may be viewed as not only a crucial platform for environmental awareness but also as a powerful vehicle for social change (Kellison \& Kim, 2014; Kellison et al., 2015), the contextually rich insight yielded from this study provided promising contributions to our understanding of how organizational forms can shift and expand in response to issues of environmental and social importance. Ideally, athletic departments can blur their organizational boundaries with the public, business, and non-profit sectors in order to become more effective at addressing contemporary issues. As demonstrated in this study, however, the perceived barrier between academics and athletics can dampen the benefits of a CSSP. To this end, our findings provide valuable information to researchers seeking to forward environmental efforts within the sport industry. For example, athletic administrators or sustainability officers can use these findings to better organize and define the roles for their Green Team members. Similarly, this study may help organizational champions better understand the importance of delegating, supporting, and yielding authority to others when leading cross-sector partnerships. Furthermore, when forming a CSSP, decision-makers may consider appointing upper-level administrators from across the university in order to maintain a balance of power between the academic and athletic arms of the institution.

Researchers examining this context in the future should consider assessing the evaluation process of the committee's set Key Performance Indicators. Additionally, our findings raise further questions that should be researched in the future including: Who are the necessary stakeholders to include when initially forming a green committee? What policies or strategies can properly empower a green committee? Can CSSPs involving athletics and other campus departments help bridge the isolation athletics has on campus? These questions and others will continue to arise as Green Teams become more commonplace on college campuses seeking to boost the sustainability efforts of their athletic departments. 


\section{References}

Agrawal, A. K. (2001). University-toindustry knowledge transfer: Literature review and unanswered questions. International Journal of Management Reviews, 3, 285-302. doi:10.1111/1468-2370.00069

Alderfer, C. P. (1980). The methodology of organizational diagnosis. Professional Psychology, 11, 459-468. doi:10.1037/0735-7028.11.3.459

Austin, J. E., \& Seitanidi, M. M. (2012a). Collaborative value creation: A review of partnering between nonprofits and businesses. Part 1: Value creation spectrum and collaboration stages. Nonprofit and Voluntary Sector Quarterly, 41, 726-758. doi:10.1177/0899764012450777

Austin, J. E., \& Seitanidi, M. M. (2012b). Collaborative value creation: A review of partnering between nonprofits and businesses. Part 2: Partnership processes and outcomes. Nonprofit and Voluntary Sector Quarterly, 41, 929-968. doi:10.1177/0899764012454685

Babiak, K. (2007). Determinants of interorganizational relationships: The case of a Canadian nonprofit sport organization. Journal of Sport Management, 21(3), 338-376.

Babiak, K. (2009). Criteria of effectiveness in multiple cross-sectoral interorganizational relationships. Evaluation and Program Planning, 32, 112. doi:10.1016/j.evalprogplan.2008.09.0 04

Babiak, K., \& Thibault, L. (2009). Challenges in multiple cross-sector partnerships. Nonprofit and Voluntary Sector Quarterly, 38, 117-143. doi:10.1177/0899764008316054

Babiak, K., \& Trendafilova, S. (2011). CSR and environmental responsibility: Motives and pressures to adopt sustainable management practices. Corporate Social Responsibility and Environmental Management, 18, 11-24. doi:10.1002/csr.229

Barringer, B., \& Harrison, J. (2000). Walking a tightrope: Creating value through interorganizational relationships. Journal of Management, 26, 367-403. doi:10.1177/014920630002600302

Boyd, B., Henning, N., Reyna, E., Wang, D. E., \& Welch, M. D. (2009). Hybrid organizations: New business models for environmental leadership. Sheffield, UK: Greenleaf.

Bryson, J. M., Crosby, B. C., \& Stone, M. M. (2006). The design and implementation of cross sector collaborations: Propositions from the literature. Public Administration Review, 66, 44-55. Retrieved from http://www.jstor.org/stable/409656 9

Buer, T. (2009). Organizational complexity: The athletics department and the university. New Directions for Higher Education, 148, 109-116. doi:10.1002/he.374 
Casper, J., Pfahl, M., \& McSherry, M.

(2012). Athletics department awareness and action regarding the environment: A study of NCAA athletics department sustainability practices. Journal of Sport Management, 26, 11-29.

Clarke, A., \& Fuller, M. (2010).

Collaborative strategy formulation and implementation by multiorganizational cross-sector social partnerships. Journal of Business Ethics, 94, 85-101. doi:10.1007/s10551-0110781-5

Cornelius, N., \& Wallace, J. (2010). Crosssector partnerships: City regeneration and social justice. Journal of Business Ethics, 94, 71-84. doi:10.1007/s10551-011-0780-6

Cunningham, G. B. (2009). Understanding the diversity-related change process: A field study. Journal of Sport Management, 23, 407-428.

Dentoni, D., \& Bitzer, V. (2015). The role(s) of universities in dealing with global wicked problems through multistakeholder initiatives. Journal of Cleaner Production, 106, 68-78. doi:10.1016/j.jclepro.2014.09.050

DiMaggio, P., \& Powell, W. (1983). The iron cage revisited: Institutional isomorphism and collective rationality in organizational fields. American Sociological Review, 48, 147160.

Doh, J. P., \& Guay, T. R. (2006). Corporate social responsibility, public policy, and NGO activism in Europe and the United States: An institutionalstakeholder perspective. Journal of Management Studies, 43, 47-73. doi:10.1111/j.14676486.2006.00582.x

Dowling, M., Robinson, L., \& Washington, M. (2013). Taking advantage of the London 2012 Olympic Games: Corporate social responsibility through sport partnerships. European Sport Management Quarterly, 13, 269_ 292. doi:10.1080/16184742.2013.774039

Frisby, W., Thibault, L., \& Kikulis, L. (2004). The organizational dynamics of undermanaged partnerships in leisure service departments. Leisure Studies, 23, 109-126.

Gerke, A., Babiak, K., Dickson, G., \& Desbordes, M. (2017). Developmental processes and motivations for linkages in crosssectoral sport clusters. Sport Management Review. doi:j.smr.2017.05.005

Getha-Taylor, H. (2012). Cross-sector understanding and trust. Public Performance \& Management Review, 36, 216-229. doi:10.2753/PMR15309576360203

Gray, B. (1989). Collaborating: Finding common ground for multiparty problems. San Francisco: Jossey-Bass Publishers. Hambrick, D. C., \& Mason, P. A. (1984). Upper echelons: The organization as a reflection of its top managers. 
Academy of Management Review, 9, 193206. Retrieved from

http://www.jstor.org/stable/258434

Hora, M. T., \& Millar, S. B. (2011). A guide

to building education partnerships:

Navigating diverse cultural contexts to turn challenge into promise. Sterling, VA:

Stylus.

Ireland, R. D., Hitt, M. A., \& Vaidyanath, D. (2002). Alliance management as a source of competitive advantage. Journal of Management, 28, 413-446. doi:10.1177/014920630202800308

Kellison, T. B., \& Kim, Y. K. (2014). Marketing pro-environmental venues in professional sport: Planting seeds of change among existing and prospective consumers. Journal of Sport Management, 28, 34-48. doi:10.1123/jsm.2011-0127

Kellison, T. B., \& McCullough, B. P. (2016). A forecast for the mainstreaming of environmental sustainability. Sport and Entertainment Review, 2, 11-18.

Kellison, T. B., \& McCullough, B. P. (2017). A pragmatic perspective on the future of sustainability in sport. In B. P. McCullough \& T. B. Kellison (Eds.), Routledge handbook of sport and the environment (pp. 445-455). New

York: Routledge.

Kellison, T.B., Trendafilova, S., \& McCullough, B.P. (2015). Considering the social impact of sustainable stadium design. International Journal of Event Management Research, 10, 63-83.
Kihl, L. A., Tainsky, S., Babiak, K., \& Bang, H. (2014). Evaluation of a crosssector community initiative partnership: Delivering a local sport program. Evaluation and Program Planning, 44, 36-47.

Le Ber, M. J., \& Branzei, O. (2010). Value frame fusion in cross sector interactions. Journal of Business Ethics, 94, 163-195. doi:10.1007/s10551011-0785-1

Lin, H. (2014). Government-business partnership formation for environmental improvements. Organization \& Environment, 27, 383398. doi:10.1177/1086026614554716

Manning, S., \& Roessler, D. (2014). The formation of cross-sector development partnerships: How bridging agents shape project agendas and longer-term alliances. Journal of Business Ethics, 123, 527-547. doi:10.1007/s10551-013-1853-5

Marchington, M., \& Vincent, S. (2004). Analysing the influence of institutional, organizational and interpersonal forces in shaping interorganizational relations. Journal of Management Studies, 41, 1029-1056. doi:10.1111/j.14676486.2004.00465.x

McCullough, B. P. (2013). Identifying the influences on sport spectator recycling behaviours using the theory of planned behaviour. International Journal of Sport Management and 
Marketing, 14(1), 146-168.

doi:10.1504/IJSMM.2013.060631

McCullough, B. P., \& Cunningham, G. B. (2010). A conceptual model to understand the impetus to engage in and the expected organizational outcomes of green initiatives. Quest, 62, 348-363. doi:10.1080/00336297.2010.1048365 4

McCullough, B. P., \& Kellison, T. B. (2017). An introduction to environmental sustainability and sport. In B. P. McCullough \& T. B. Kellison (Eds.), Routledge handbook of sport and the environment (pp. 4-10). New York: Routledge.

McCullough, B. P., Trendafilova, S., \& Picariello, M. (2016). Legitimizing sustainability efforts through strategic partnerships. Sport \& Entertainment Review, 2(3), 77-83.

McCullough, B. P., Pfahl, M., \& Nguyen, S. (2016). The green waves of environmental sustainability in sport. Sport in Society: Cultures, Commerce, Media, Politics, 19(7), 1040-1065. doi:10.1080/17430437.2015.1096251

Meenaghan, T. (1998). Current developments \& future directions in sponsorship. International Journal of Advertising, 17(1), 3-28.

Misener, K., \& Doherty, A. (2013). Understanding capacity through the processes and outcomes of interorganizational relationships in nonprofit community sport organizations. Sport Management Review, 16(2), 135-147.

Murphy, M., Perrot, F., \& Rivera-Santos, M. (2012). New perspectives on learning and innovation in cross-sector collaborations. Journal of Business Research, 65, 1700-1709. doi:10.1016/j.jbusres.2012.02.011

Natural Resources Defense Council. (2013). Collegiate game changers: How campus sport is going green. Retrieved from http://www.nrdc.org

Nelson, J., \& Zadek, S. (2000). Partnership alchemy: New social partnerships in Europe. Copenhagen: Copenhagen Centre.

Nichols, J. S., Corrigan, T. F., \& Hardin, M. (2011). Integration of athletics and academics: Survey of best practices at FBS schools. Journal of Intercollegiate Sport, 4, 107-120.

Nguyen, S., Trendafilova, S., \& Pfahl, M. (2014). The natural resource-based view of the firm (NRBV): constraints and opportunities for a green team in professional sport. International Journal of Sport Management, 15(4), 485-517.

Parker, A., \& Crona, B. I. (2012). On being all things to all people: Boundary organizations and the contemporary research university. Social Studies of Science, 42, 1-28. doi:10.1177/0306312711435833

Pfahl, M. (2010). Strategic issues associated with the development of internal sustainability teams in sport organizations: A framework for 
action and sustainable environmental performance. International Journal of Sport Management, Recreation, and Tourism, 6, 37-61. doi:10.5199/ijsmart-1791-874X-6c

Pfahl, M. (2013). The environmental awakening in sport. The Solutions Journal, 4, 67-76.

Pfahl, M., Casper, J., Trendafilova, S., McCullough, B. P., \& Nguyen, S. N. (2015). Crossing boundaries: An examination of sustainability department and athletics department collaboration regarding environmental issues. Communication \& Sport, 3, 27-56. doi:10.1177/2167479513519253.

Pfeffer, J., \& Salancik, G. R. (1978). The external control of organizations. New York: Harper \& Row.

Ponterotto, J. G. (2005). Qualitative research in counseling psychology: A primer on research paradigms and philosophy in science. Journal of Counseling Psychology, 52, 126-136. doi:10.1037/0022-0167.52.2.126

Rod, M. R. M., \& Paliwoda, S. J. (2003). Multi-sector collaboration: a stakeholder perspective on a government, industry and university collaborative venture. Science \& Public Policy, 30, 273-284. doi:03023427/03/040273-12

Rondinelli, D. A., \& London, T. (2003). How corporations and environmental groups cooperate: Assessing crosssector alliances and collaborations.
Academy of Management Executive, 17, 61-76. Retrieved from http://www.jstor.org/stable/416592 9

Sartore-Baldwin, M. L. \& McCullough, B. P. (in press). Equity-based sustainability and ecocentric management: Creating more ecologically just sport organization practices. Sport Management Review, 1-12. doi: 10.1016/j.smr.2017.08.009

Sartore-Baldwin, M. L., McCullough, B. P. \& Quatman-Yates, C. (2017). Shared responsibility and issues of injustice and harm within sport. Quest, 69(7), 366-383. doi:10.1080/00336297.2016.1238769

Schroeder, C.C. (1999). Forging educational partnerships that advance student learning. In G. S. Blimling \& E. J. Whitt (Eds.), Good practice in student affairs: Principles to foster student learning (pp. 133-156). San Francisco, CA: Jossey-Bass.

Schwandt, T. A. (2007). The Sage dictionary of qualitative inquiry (3rd ed.). Thousand Oaks, CA: Sage.

Seitanidi, M. M., Koufopoulos, D. N., \& Palmer, P. (2010). Partnership formation for change: Indicators for transformative potential in cross sector partnerships. Journal of Business Ethics, 94, 139-161. doi:10.1007/s10551-011-0784-2

Selsky, J. W., \& Parker, B. (2005). Crosssector partnerships to address social issues: Challenges to theory and 
practice. Journal of Management, 31,

849-873.

doi:10.1177/0149206305279601

Selsky, J. W., \& Parker, B. (2010). Platforms

for cross-sector social partnerships:

Prospective sensemaking devices for

social benefit. Journal of Business Ethics, 94, 21-37. doi:10.1007/210551-011-

0776-2

Siegel, D. J. (2010). Why universities join cross-sector social partnerships:

Theory and evidence. Journal of Higher Education Outreach and Engagement, 14, 33-62. Retrieved from

http://openjournals.libs.uga.edu/ind ex.php/jheoe/index

Steward, F., \& Conway, S. (1998). Situating discourse in environmental innovation networks. Organization, 5 , 479-502.

Townsley, S. R. (2014). Nurturing a new interdependence: Examining role change and perspective shifts in cross-sector social partnerships (Unpublished doctoral dissertation). Saybrook University, Oakland, CA.

Wassmer, U., Paquin, R., \& Sharma, S. (2014). The engagement of firms in environmental collaborations: Existing contributions and future directions. Business \& Society, 53, 754786. doi:10.1177/0007650312439865

Wohlstetter, P., Smith, J., \& Malloy, C. L. (2005). Strategic alliances in action: Toward a theory of evolution. Policy

Studies Journal, 33, 419-442.

doi:10.1111/j.1541-0072.2005.00123 


\section{Tables}

Table 1

Interview Participant Details

\begin{tabular}{lcll}
\hline Pseudonym & $\begin{array}{c}\text { Years on Green } \\
\text { Team }\end{array}$ & \multicolumn{1}{c}{ Department } & \multicolumn{1}{c}{ Status } \\
\hline Joan & 5 & Athletics-Administration & professional \\
Tim & 3 & $\begin{array}{l}\text { Athletics-Administration } \\
\text { Athletics-Student-Athlete }\end{array}$ & professional \\
John & 2 & Support & professional \\
Mark & 1 & Athletics-Ticketing & professional \\
Samantha & 2 & Concessions & professional \\
Melissa & 3 & Waste Management & professional \\
Steve & 4 & Athletics-Facilities & student \\
Nicole & 2 & Athletics-Student-Athlete & professional \\
Brian & 2 & Office of Sustainability & professional \\
Ronan & 3 & Office of Sustainability & professional \\
Patrick & 1 & Office of Sustainability &
\end{tabular}

